\title{
Diagnosis of venous and arterial thromboembolic events in COVID-19 virus-infected patients
}

\author{
Anna Betoule ${ }^{1}$ D $\cdot$ Camille Martinet $^{1} \cdot$ Guillaume Gasperini $^{1} \cdot$ Pauline Muller $^{1} \cdot$ Stéphane Foucher $^{1} \cdot$ Patrick Benner $^{1}$. \\ Aurélien Renard ${ }^{1}$
}

Published online: 5 June 2020

○) Springer Science+Business Media, LLC, part of Springer Nature 2020

The COVID-19 pandemic affects more than two million people to date with a high prevalence of thromboembolic events (TEE) and disseminated intravascular coagulation (DIC) [1, 2]. Tang et al. [3] recently reported that it would be beneficial to start anticoagulation in patients infected with COronaVirus Infectious Disease 2019 (COVID-19) and having a sepsis-induced coagulopathy (SIC) score $\geq 4$ or D-dimers $>3 \mu \mathrm{g} / \mathrm{ml}$.

We wanted to see whether these recommendations could be effective for the participating patients in this trial.

In our hospital emergency unit, over a period of 3 weeks, we evaluated the prevalence of venous or arterial thromboembolic disease in patients diagnosed with COVID-19. The criteria for a positive diagnosis for COVID-19 was based either on the positive test result of RT-PCR after a nasopharyngeal swab [4] or a chest scan [5]. The data was collected retrospectively from the patients' electronic medical records. The first results were retained. No patient was excluded, and the research committee of our hospital approved this study.

The criteria for severe COVID-19 [6], the SOFA score (Sepsis-related Organ Failure Assessment score), the DIC score (proposed by the International Society on Thrombosis and Haemostasis-ISTH) (Table 1) and the SIC score (Table 2) were calculated for each patient $[1,7,8]$.

From 13th March 2020 to 6th April 2020, we included 76 patients infected with COVID-19. The proportion of men and women was similar, with an average age of 62 years. Fifty-seven $(75 \%)$ patients had one or more chronic diseases, including hypertension (32.9\%) and diabetes $(13.1 \%)$. Thirty-one $(25.14 \%)$ patients had severe COVID-19 criteria upon arrival. Fifteen (17\%) patients were able to return

Anna Betoule

anna.betoule@intradef.gouv.fr

1 Service d'accueil des urgences, Hôpital D'instruction Des armées Sainte Anne, Toulon, France home, while 13 (19\%) patients were admitted to intensive care unit. Five patients $(8 \%)$ had a SIC score of $\geq 4$, seven patients $(9 \%)$ had a D-dimer level of $\geq 3 \mu \mathrm{g} / \mathrm{ml}$ and three patients $(4 \%)$ have died to date.

Five patients $(6.6 \%)$ were diagnosed in the emergency department with a TEE (two pulmonary embolisms, one acute leg ischemia and two strokes). We noticed that a higher DIC score (ISTH) was associated with an increased risk of thromboembolic disease $(p=0.0007)$ (3.00 on average versus 1.73 for the group without TEE). However, we were unable to prove this link in regard to the SIC score $(\mathrm{p}=0.9824)$ and the SOFA score $(p=0,675)$. A significantly $(p=0.0012)$ higher D-dimer rate was observed with patients that suffered from TEE (average $=15.83$ [95\% CI 14.69-16.96]), compared to those who were spared (average 1.18, [95\% CI 0.86-1.50]) (Fig. 1).

The results of the SIC score seem to be lower than the DIC score (ISTH) alone in order to predict the occurrence of TEE (Fig. 2). The level of D-dimer has a good predictive value for the occurrence of arterial or venous TEE in patients with COVID-19. In our trial included of few patients, the population was less severe than that of Tang et al. [3]. This could explain the differences observed between the mortality rates and the SIC scores.

Thus, the D-dimers appear to be more discriminating in suspecting a TEE than the SIC score. The DIC score is not intended to screen for TEE but to screen for DIC, however it remains an interesting approach. To conclude, the only value that D-dimer $\geq 3 \mu \mathrm{g} / \mathrm{ml}$ can lead to a discussion on the implementation of preventive anticoagulant treatments once COVID-19 is diagnosed. This observation, based on a simple biological test, can be of interest to emergency doctors exposed to a large number of patients who show symptoms of the disease that vary in terms of their characteristics and severity.

In order to remedy the inaccuracies of these scores, it seems necessary to include anamnestic and biological 
Table 1 DIC score (ISTH)

\begin{tabular}{lll}
\hline ITEM & Range & Score \\
\hline Platelet count $\left(\times 10^{9} / \mathrm{l}\right)$ & $>100$ & 0 \\
& $50-100$ & 1 \\
& $<50$ & 2 \\
D-dimer $(\mu \mathrm{g} / \mathrm{ml})$ & $<1$ & 0 \\
& $1-5$ & 2 \\
Fibrinogen $(\mathrm{g} / \mathrm{l})$ & $>5$ & 3 \\
& $>1$ & 0 \\
Prothrombin time prolongation & $\leq 1$ & 1 \\
& $<3 \mathrm{~s}$ & 0 \\
Total score for DIC & $3-6 \mathrm{~s}$ & 1 \\
\end{tabular}

Table 2 SIC score

\begin{tabular}{lll}
\hline Item & Range & Score \\
\hline Platelet count $\left(\times 10^{9} / \mathrm{L}\right)$ & $100-150$ & 1 \\
& $<100$ & 2 \\
PT-INR (International Normalized & $1.2-1.4$ & 1 \\
Ratio) & $>1.4$ & 2 \\
SOFA score & 1 & 1 \\
& $\geq 2$ & 2 \\
Total score for SIC & & $\geq 4$ \\
\hline
\end{tabular}

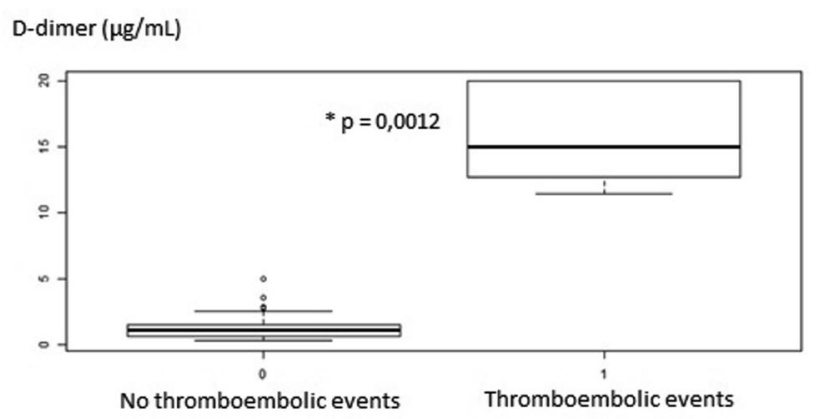

Fig. 1 D-dimer levels are associated with the occurrence of TEE

elements such as BMI, thromboembolic disease risk factors, long-term anticoagulant treatments and the importance of inflammatory syndromes [9]. A larger prospective study would enable us to further validate its diagnostic and prognostic value.

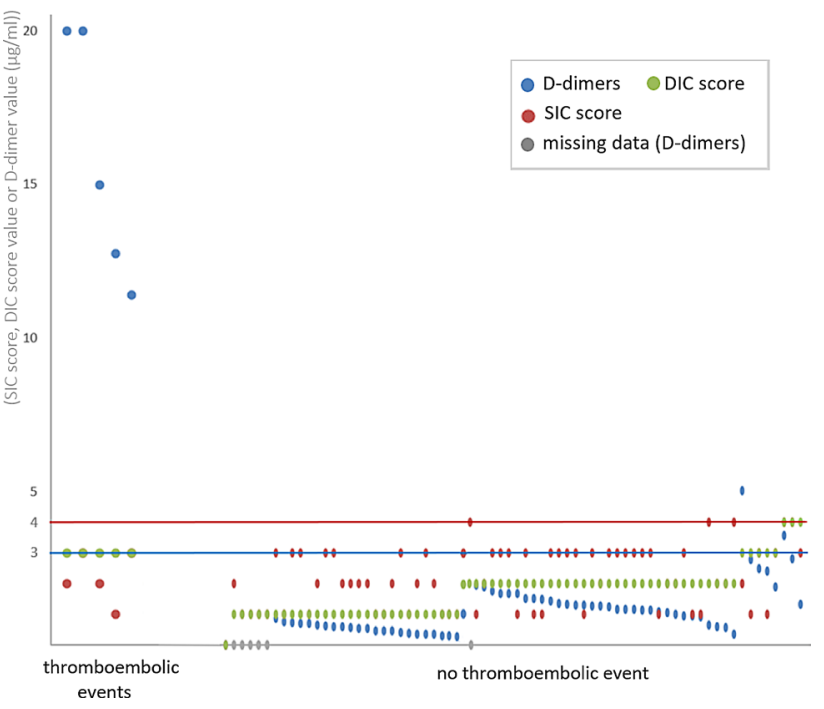

Fig. 2 D-dimer levels, SIC score and DIC score according to the existence of a TEE

\section{Compliance with ethical standards}

Conflict of interest The authors have no financial or other conflicts of interest.

\section{References}

1. Chen N, Zhou M, Dong X et al (2020) Epidemiological and clinical characteristics of 99 cases of 2019 novel coronavirus pneumonia in Wuhan, China: a descriptive study. Lancet 395(10223):507513. https://doi.org/10.1016/S0140-6736(20)30211-7

2. Tang N, Li D, Wang X, Sun Z (2020) Abnormal coagulation parameters are associated with poor prognosis in patients with novel coronavirus pneumonia. J Thromb Haemost 18(4):844-847. https://doi.org/10.1111/jth.14768

3. Tang N, Bai H, Chen X, Gong J, Li D, Sun Z (2020) Anticoagulant treatment is associated with decreased mortality in severe coronavirus disease 2019 patients with coagulopathy. J Thromb Haemost. https://doi.org/10.1111/jth.14817

4. WHO (2020) Clinical management of severe acute respiratory infection when COVID-19 is suspected. IOP Publishing World Health Organization. https://www.who.int/publications-detail/ clinical-management-of-severe-acute-respiratory-infection-whennovel-coronavirus-(ncov)-infection-is-suspected. Accessed $10 \mathrm{Apr}$ 2020

5. Bai HX, Hsieh B, Xiong Z, Halsey K, Choi JW, Tran TML et al (2020) Performance of radiologists in differentiating COVID-19 from viral pneumonia on chest CT. Radiology 10:200823. https ://doi.org/10.1148/radiol.2020200823

6. National Health Commission of China (2020) The diagnosis and treatment plan for the novel coronavirus disease, 7 th edn. National Health Commission of China, Beijing

7. Singer M, Deutschman CS, Seymour CW et al (2016) The third international consensus definitions for sepsis and septic shock (Sepsis-3). JAMA 315(8):801-810. https://doi.org/10.1001/ jama.2016.0287 
8. Iba T, Levy JH, Warkentin TE, Thachil J, Poll T, Levi M et al (2019) Diagnosis and management of sepsis-induced coagulopathy and disseminated intravascular coagulation. J Thromb Haemost 17(11):1989-1994. https://doi.org/10.1111/jth.14578

9. Susen S, Tacquard CA, Godon A, Mansour A, Garrigue D, Nguyen $P$ et al (2020) Traitement anticoagulant pour la prévention du risque thrombotique chez un patient hospitalisé avec Covid-19 et surveillance de l'hémostase. IOP Publishing Société Française d'Anesthésie et de Réanimation. https://sfar.org/traitement-antic oagulant-pour-la-prevention-du-risque-thrombotique-chez-unpatient-hospitalise-avec-covid-19-et-surveillance-de-lhemostase . Accessed 8 Apr 2020

Publisher's Note Springer Nature remains neutral with regard to jurisdictional claims in published maps and institutional affiliations. 